\begin{tabular}{|l|l|}
\hline Postprint Version & 1.0 \\
\hline Journal website & $\underline{\mathrm{http}: / / \mathrm{dx} . d o i . o r g / 10.1080 / 08870440902853215}$ \\
\hline Pubmed link & $\underline{\mathrm{http}: / / \text { www.ncbi.nlm.nih.gov/pubmed/20204947 }}$ \\
\hline DOI & $10.1080 / 08870440902853215$ \\
\hline
\end{tabular}

This is a NIVEL certified Post Print, more info at http://www.nivel.eu

\title{
Perceived autonomy and self-esteem in Dutch dialysis patients: The importance of illness and treatment perceptions
}

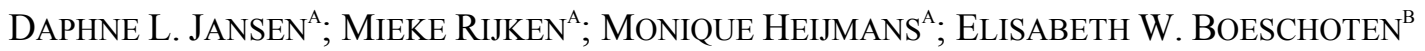 \\ ${ }^{a}$ NIVEL, Netherlands Institute for Health Services Research, 3500 BN Utrecht, The Netherlands

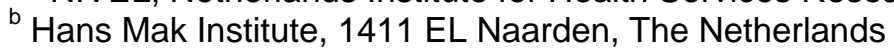

\begin{abstract}
Compared to healthy people, end-stage renal disease (ESRD) patients participate less in paid jobs and social activities. This study explored the perceived autonomy, state self-esteem and labour participation in ESRD patients on dialysis, and the role illness and treatment perceptions play in these concepts. Patients completed questionnaires at home or in the dialysis centre $(N=$ 166). Data were analysed using bivariate and multivariate analyses. Labour participation among dialysis patients was low, the average autonomy levels were only moderate, and the average self-esteem level was rather high. On the whole, positive illness and treatment perceptions were associated with higher autonomy and self-esteem, but not with labour participation. Multiple regression analyses demonstrated that illness and treatment perceptions explained 18 to $27 \%$ of the variance in autonomy and self-esteem. Perceptions of personal control, less impact of the illness and treatment, and less concern were important predictors. Our results indicate that dialysis patients' beliefs about their illness and treatment play an important role in their perceived autonomy and self-esteem. Stimulating positive (realistic) beliefs and altering maladaptive beliefs might contribute to a greater sense of autonomy and self-esteem, and to social participation in general. Interventions focusing on these beliefs may assist patients to adjust to ESRD.
\end{abstract}

\section{INTRODUCTION}

End-stage renal disease (ESRD) is a chronic condition which is becoming more common worldwide. In this stage of the disease, patients have to start with renal replacement therapy (haemodialysis, peritoneal dialysis, renal transplantation). At the end of 2004, approximately 1,783,000 people worldwide were undergoing treatment for ESRD (Grassmann, Gioberge, Moeller, \& Brown, 2005). In January 2006, 12,038 people in the Netherlands received renal replacement therapy (737 people per million Dutch residents) (Oppe, Treur, Barendregt, \& de Charro, 2007). ESRD is characterised by specific disease aspects and intensive treatment demands. ESRD patients on dialysis experience multiple symptoms, with pain, fatigue, pruritus and constipation in the majority of the patients (Murtagh, Addington-Hall, \& Higginson, 2007). In addition, the dialysis treatment is very time consuming and places a large burden on patients' daily lives. Having ESRD and receiving renal replacement therapy has many consequences for different domains of life. Results of a literature study (Heijmans \& Rijken, 2004) show that compared to healthy people, renal patients who are being prepared for, or receive renal replacement therapy participate less in paid jobs, 
Jansen, D.L., Rijken, M., Heijmans, M., Boeschoten, E.W. Perceived autonomy and self-esteem in Dutch dialysis patients: the importance of illness and treatment perceptions. Psychology \& Health: 2010, 25(6), 733-749

sports and other social and leisure activities. A study among Dutch renal transplant patients revealed that in these patients participation in employment and sports is lower than healthy persons (Van der Mei et al., 2007). Thus, having ESRD and undergoing treatment has a negative impact on participation in different domains of life.

Restriction of the number of activities or the quality of activities can have serious drawbacks for a person's feelings of autonomy and self-esteem. According to Deci and Ryan's (1985) self-determination theory, autonomy is one of people's basic psychological needs, and satisfaction of this need is linked to well-being. Reis, Sheldon, Gable, Roscoe, and Ryan (2000) found that perceived autonomy independently predicted daily well-being. State self-esteem refers to the feelings of self-worth depending on a person's experience. Crocker and Wolfe (2001) proposed that good and bad events in domains in which self-esteem is invested raise or lower momentary feelings of self-esteem around a person's trait level of self-esteem. Paradise and Kernis (2002) found that high self-esteem and stable self-esteem were associated with greater psychological well-being.

In addition to autonomy and self-esteem, labour participation is considered important for well-being. A review of the literature showed that there is strong evidence that work is generally good for physical and mental health and well-being, taking into account the nature and quality of work and its social context (Waddell \& Burton, 2006). A study among haemodialysis patients showed that, compared to patients without work, working patients have increased self-esteem, higher quality of life, and more positive attitudes towards work (Rasgon et al., 1993).

Little is known about the factors that impede perceived autonomy, (state) self-esteem and labour participation in ESRD patients. Obviously, socio-demographic characteristics like age, and clinical characteristics like severity of the illness are important. Results from the literature study of Heijmans and Rijken (2004) suggest that psychological factors may be important determinants of labour participation and perceived autonomy of renal patients as well. In particular, the way patients perceive their illness might play a role. A study by Braun Curtin, Oberly, Sacksteder, and Friedman (1996) demonstrates that dialysis patients with and without a paid job differed regarding their attitudes towards work. Patients with a job did not feel limited by their illness during the hours they worked, and did not feel limited with respect to the type of work they could do. Patients without work on the other hand, perceived their illness as a barrier to find work. These findings are interesting since both patient groups did not differ with respect to illness severity and treatment modality.

Patients' beliefs about their illness are the central concepts of the Common Sense Model (CSM) (Leventhal, Meyer, \& Nerenz, 1980; Leventhal, Nerenz, \& Steele, 1984). This model suggests that individuals hold certain views about their illness which in turn determine how they respond on a behavioural and emotional level to their illness. Individuals' illness representations include beliefs about symptoms, the causes and prognosis of the illness, the consequences of the illness and the possibilities for control. Research among patients with various medical conditions shows that illness perceptions are associated with various outcomes, including role, social and physical functioning, vitality, psychological well-being, and self-management (Hagger \& Orbell, 2003; Petrie, Jago, \& Devcich, 2007). Besides illness representations, patients' ideas about treatment also play a role in the way patients cope with their illness (Horne, 2003; Horne et al., 2004).

In the literature, several studies examined the illness and treatment perceptions of renal patients (e.g. Griva, Jayasena, Davenport, Harrison, \& Newman, 2009; Timmers et al., 2008). Illness and treatment perceptions appeared to be more favourable in transplanted patients compared to dialysis patients (Griva et al., 2009), and peritoneal dialysis (PD) patients held more favourable illness perceptions compared to patients treated with haemodialysis (HD) (Timmers et al., 2008). Furthermore, the studies showed that illness perceptions and treatment perceptions contribute significantly to several aspects of quality of life. More perceived symptoms, more perceived negative consequences and a lower personal control were associated with a lower level of well-being (Timmers et al., 2008).

So far, no studies have been conducted with respect to the role of illness and treatment perceptions in perceived autonomy, self-esteem and labour participation in renal patients. An interesting study among myocardial infarction (MI) patients, however, showed that illness perceptions are related to return to work (Petrie, Weinman, Sharpe, \& Buckley, 1996). In particular, perceptions about the duration and the consequences of the illness predicted the speed of return to work. Inspired by these promising results, the aim of the present study was to examine the role of illness and treatment perceptions in perceived 
Jansen, D.L., Rijken, M., Heijmans, M., Boeschoten, E.W. Perceived autonomy and self-esteem in Dutch dialysis patients: the importance of illness and treatment perceptions. Psychology \& Health: 2010, 25(6), 733-749

autonomy, state self-esteem and labour participation of dialysis patients. The following research questions were formulated:

1. To what extent do dialysis patients experience autonomy, and state self-esteem and participate in the work domain, and are there differences in perceived autonomy, state self-esteem and labour participation according to socio-demographic and clinical characteristics?

2. To what extent are illness and treatment perceptions in dialysis patients related to perceived autonomy, state self-esteem and labour participation?

\section{METHODS}

\section{Participants and procedure}

Dialysis patients who were participating in the longitudinal Netherlands Cooperative Study on the Adequacy of Dialysis phase 2 (NECOSAD-2) (Termorshuizen et al., 2003; Timmers et al., 2008), were invited to participate in the present study. The NECOSAD-2 study was approved by the Medical Ethical Committees of the participating dialysis centres and hospitals. Inclusion criteria were: being older than 18 years, and having no previous history of renal replacement therapy. Since 1997, more than 2000 dialysis patients were recruited. Within NECOSAD-2 clinical and quality of life data are collected every 6 months. For the present study, an additional survey was conducted in March/April 2006 among the 248 patients still being followed in the NECOSAD-2 cohort. The questionnaires were handed out by the nurses in the dialysis centres. Patients filled in the questionnaires at home or in the dialysis centre and returned them by mail. Out of the 248 patients contacted, 166 patients returned the questionnaire (response rate $67 \%$ ).

\section{MEASURES}

\section{Outcome variables}

Perceived autonomy was assessed with three items derived from the autonomy scale of the CASP-19 (Hyde, Wiggins, Higgs, \& Blane, 2003), which has been used in several studies (Marmot, Banks, Blundell, Lessof, \& Nazroo, 2003; Taylor, Brice, Buck, \& Prentice-Lane, 2003). One item 'My health stops me from doing the things I want to do' (reverse scored) was used as an indicator for 'health related autonomy'. The other two items were combined on the basis of their high factor loadings on one factor (both factor loadings: 0.81 , variance explained: $66 \%$ ) to assess 'global autonomy' ('I can do the things that I want to do', 'I feel that I can please myself what I can do'). Items were scored on a 4-point scale $(0=$ never, $1=$ sometimes, 2 = not so often, 3 = often). Global autonomy scores are expressed as average scores based on the two items. Higher scores on both measures signify a higher level of perceived autonomy.

State self-esteem was measured with the Current Thoughts Scale (Heatherton \& Polivy, 1991), which comprises 20 items (e.g. 'I am worried about what other people think of me' (reverse scored)). Items were rated on a 5 -point scale $(1=$ not at all, $2=$ a little bit, $3=$ somewhat, $4=$ very much, $5=$ extremely $)$. Scores are summed across individual ratings with higher scores representing a higher level of state self-esteem. The scale has been used in several studies (Baumeister, DeWall, Ciarocco, \& Twenge, 2005; Chang \& Mackenzie, 1998). The Cronbach's alpha for the scale in the current study was 0.88 .

Labour participation was defined in conformity with Statistics Netherlands (CBS), as performance of paid work for at least $12 \mathrm{~h}$ per week.

\section{Predictor variables}

Illness perceptions were assessed using the Brief Illness Perception Questionnaire (Broadbent, Petrie, Main, \& Weinman, 2006). This scale is a brief version of the Revised IPQ (Moss-Morris et al., 2002). The scale includes eight items scored on an 11-point scale, ranging from 0 to 10. Each item assesses a cognitive illness representation dimension. A higher score on the eight dimensions implies greater perceived influence of the illness upon life ('consequences'), a stronger belief in a chronic time course ('timeline'), greater perceived personal control over the illness ('personal control'), greater perceived treatment control over the illness ('treatment control'), greater experience of severe symptoms as a result of the illness ('identity'), greater feelings of concern about the illness ('concern'), better understanding of the illness ('understanding') and stronger emotional response to the illness ('emotional response'). A ninth open-ended response item assessing the patients' causal representation was not included in the study. The Brief IPQ has 
Jansen, D.L., Rijken, M., Heijmans, M., Boeschoten, E.W. Perceived autonomy and self-esteem in Dutch dialysis patients: the importance of illness and treatment perceptions. Psychology \& Health: 2010, 25(6), 733-749

proven to be a reliable and valid measure of illness perceptions in a variety of illness populations (Broadbent et al., 2006).

Treatment perceptions were assessed with the Treatment Effects Questionnaire (TEQ; originally developed as the IEQ-Tx by Greenberg and Peterson (2002); adapted by Griva et al. (2009)). The TEQ consists of 20 items (e.g. 'My life revolves around this treatment'), scored on an 8-point scale $(0=$ strongly disagree to $7=$ strongly agree). Scores are summed across individual ratings with higher scores indicating greater perceived disruption from the treatment. The TEQ has been used in a study with ESRD patients (Griva et al., 2009). The Cronbach's alpha for the scale in the current study was 0.91 .

\section{Background variables}

Socio-demographic characteristics included age, gender, marital status 1 and educational level. Marital status was defined as married/living together versus living alone. Educational level was defined as the highest level of completed education and classified as low (primary education, lower secondary and lower vocational education), moderate (intermediate secondary and intermediate vocational education) and high (higher vocational education and university).

Clinical characteristics included time on dialysis (in years), type of dialysis treatment (HD/PD) ${ }^{1}$, and severity of the health condition. Severity of the health condition was determined by the level of serum albumin. Serum albumin is an important predictor of patient morbidity and mortality in dialysis patients (Blake, Flowerdew, Blake, \& Oreopoulos, 1993; Churchill et al., 1992; Lowrie \& Lew, 1990; Plantinga et al., 2007).

\section{STATISTICAL ANALYSIS}

Differences between the non-responders and responders regarding socio-demographic and clinical characteristics were tested by means of Student's $t$ and Chi-square tests.

In order to answer the first research question, descriptive statistics were computed to describe the extent to which dialysis patients participate in the work domain and experience autonomy and self-esteem.

Relationships between background variables on the one hand and labour participation, perceived autonomy and self-esteem on the other hand were assessed by use of analysis of variance (ANOVA) and Chi-square tests.

In order to answer the second research question, associations between illness perceptions, treatment perceptions and perceived autonomy, self-esteem, labour participation were analysed by means of Pearson's correlation coefficients and Student's $t$-test. Furthermore, hierarchical multiple linear regression analyses were performed, using the enter method, to examine the effect of illness and treatment perceptions on perceived autonomy and state self-esteem, with adjustment for socio-demographic and clinical characteristics. Three blocks of variables were entered separately; block 1: Socio-demographic variables (age, gender, marital status, educational level); block 2: Clinical variables (time on dialysis, type of dialysis treatment, severity of the health condition); block 3: Illness and treatment perceptions variables. Due to small sample sizes we were not able to perform a regression analysis with regard to labour participation.

\section{RESULTS}

\section{Study sample}

Characteristics of the total sample are outlined in Table 1. Approximately, two-thirds of the study sample were male which corresponds with the figures of the population of ESRD patients in the Netherlands (61\%) (Stichting Renine, 2005). Around two-thirds of the participants were 65 years or older. Compared with figures of the Dutch dialysis population in 2006 (49\% 65 years or older) (Oppe et al., 2007), our sample comprised a higher percentage of older patients. A large majority of respondents $(71 \%)$ were treated with $\mathrm{HD}$, which is comparable with the percentage HD patients within the Dutch dialysis population (74\%) (Stichting Renine, 2005).

\section{[TABLE 1]}

No significant differences between the study sample and the non-responders were found with regard to gender, age, marital status, type of treatment, time on dialysis and serum albumin level. 
Jansen, D.L., Rijken, M., Heijmans, M., Boeschoten, E.W. Perceived autonomy and self-esteem in Dutch dialysis patients: the importance of illness and treatment perceptions. Psychology \& Health: 2010, 25(6), 733-749

\section{Perceived autonomy}

The mean global autonomy score of the total sample was 1.60, which indicates that patients do not often experience a sense of autonomy in daily life (Table 2). ANOVA analysis showed differences with regard to educational level $(F(2,146)=3.29, p=0.040)$ : high-educated patients had significantly higher scores on global autonomy than low-educated patients. A mean score of 1.21 on the health related perceived autonomy item indicates that patients sometimes experience health related autonomy (Table 2). No significant differences were found with respect to socio-demographic and clinical characteristics

\section{[TABLE 2]}

\section{State self-esteem}

The mean state self-esteem score of the total patient group was 76.47, which indicates a rather high level of state self-esteem (Table 2). ANOVA analysis demonstrated that men scored higher on state self-esteem compared to women $(F(1,152)=4.05, p=0.046)$. No significant differences were found with regard to the other background characteristics.

\section{Labour participation}

Sixty-two people were of working age (18-64 years). Fifteen people performed paid work for at least $12 \mathrm{~h}$ per week (24\%), which is much lower than the general Dutch population; in 2006, the labour participation grade among the Dutch population aged 15-64 years was 65\% (CBS, 2006). Patients who worked were working for $32.4 \mathrm{~h}$ per week on average (range $12-40 \mathrm{~h}$ ). Forty-one people $(66 \%)$ were not employed (for at least $12 \mathrm{~h}$ per week). The employment status of six people (10\%) was unknown. The results of the ANOVA analysis showed that employed patients were significantly younger than unemployed patients $(F(1,54)=$ $7.88, p=0.007)$. No significant differences were found with regard to the other background variables.

\section{ILLNESS AND TREATMENT PERCEPTIONS}

Mean illness perceptions scores indicate that dialysis patients, as a group, consider their illness to be chronic with rather serious consequences, experience quite a few symptoms from the illness, are fairly concerned about their illness, but experience rather little emotional impact from the illness. In addition, patients reported a considerable degree of understanding and consider their illness to be highly controllable with medical treatment but not by self-care. Furthermore, patients experience moderate disruption from the treatment (Table 2).

Pearson's correlations coefficients between the illness and treatment perceptions were all below 0.60 , except for the correlation of emotional response with concern and treatment disruption (Table 2). Patients with a stronger illness identity experience more consequences from the illness and treatment, less personal control, more concern and a stronger emotional response. At the same time, they believe to have a better understanding of their illness. As patients experience more impact from the illness and treatment, they experience more severe symptoms, have more concern, have a stronger emotional response and believe they have little personal control. Personal control and treatment control are both correlated with understanding.

\section{ASSOCIATIONS BETWEEN ILLNESS AND TREATMENT PERCEPTIONS AND OUTCOME VARIABLES}

Pearson's correlations between illness and treatment perceptions on the one hand and perceived autonomy and state self-esteem on the other hand, show a consistent pattern with stronger beliefs in the seriousness of the illness being associated with lower perceived autonomy and less state self-esteem (Table 2). A stronger belief that the treatment disrupts daily life was also associated with low perceived autonomy and low state self-esteem. The dimension timeline was not associated with perceived autonomy and state-self esteem.

Within the group of working age, the relationships between labour participation (unemployed vs. employed) and the illness and treatment perceptions were also examined. Greater experience of severe symptoms as a result of the illness was significantly associated with unemployment $(t(41.846)=2.17, p=$ 0.036). The other perceptions were not significantly associated with labour participation (Table 3 ). 
Jansen, D.L., Rijken, M., Heijmans, M., Boeschoten, E.W. Perceived autonomy and self-esteem in Dutch dialysis patients: the importance of illness and treatment perceptions. Psychology \& Health: 2010, 25(6), 733-749

\section{[TABLE 3]}

\section{PREDICTING PERCEIVED AUTONOMY AND STATE SELF-ESTEEM}

Since emotional response was highly correlated with both concern and treatment disruption and the correlation between concern and treatment disruption was below 0.60 (Table 2), we decided not to include the dimension emotional response in the following regression analyses for reasons of multi-collinearity.

First, regression analysis was conducted with global autonomy being the outcome variable. The results revealed that the socio-demographic variables (block 1) explained only $4 \%$ of the variance in global autonomy (Table 4). High-educational level appeared to be a significant predictor. In model two the clinical variables were added, increasing the explained variance by only $2 \%$. In addition to a high education, being treated with PD appeared to be a significant predictor. Adding the illness and treatment perceptions to the model (block 3 ) the percentage of explained variance was increased to $24 \%$. Apart from educational level, a perception of high personal control contributed significantly to the explanation of perceived global autonomy.

\section{[TABLE 4]}

The results of the regression analysis with health related perceived autonomy being the outcome variable (Table 5) demonstrated that only the third model, in which the illness and treatment perceptions were added, explained a substantial amount of variance (18\%) with perceptions of less consequences of the illness and less impact of the treatment being the only significant contributors to perceived health related autonomy.

\section{[TABLE 5]}

Finally, we conducted a regression analysis with state self-esteem being the outcome variable. Table 6 shows that again the socio-demographic variables (block 1) and the clinical variables (block 2) did not explain any substantial amount of variance. However, in the final model in which the illness and treatment perceptions were included, the percentage of explained variance increased by $27 \%$. Less concern about the illness and less perceived disruption from the treatment appeared to be significant predictors of state selfesteem.

\section{[TABLE 6]}

\section{DISCUSSION}

The present study was conducted to examine perceived autonomy, state self-esteem and labour participation in ESRD patients who are on dialysis treatment, and to investigate the extent to which illness and treatment perceptions are related to perceived autonomy, state self-esteem and labour participation in dialysis patients.

The results confirmed previous findings that ESRD patients on dialysis participate less in the work domain (Braun Curtin et al., 1996; De Wit, Polder, Jager, \& Charro, 2001; Van Manen et al., 2001). Only 15 out of the 62 patients of working age indicated to perform paid work for at least $12 \mathrm{~h}$ per week. Furthermore, the average reported levels of perceived autonomy were not very high, which indicates that because of their health condition or otherwise patients feel less autonomous in their lives.

Correlational analyses showed that patients who held more positive beliefs about the illness and treatment experienced more autonomy (both global and health related). The results of the regression analysis confirmed these findings; illness and treatment beliefs explained a large amount of variance in predicting both global and health related perceived autonomy after controlling for socio-demographic and clinical variables. Perceptions about the personal controllability of the illness appeared to be an important predictor of global autonomy; experiencing the ability to personally control the illness is associated with autonomy feelings.

In light of these findings it is important to address the difference between the constructs personal control and autonomy, since autonomy is often incorrectly equated with ideas of internal locus of control (Deci \& 
Jansen, D.L., Rijken, M., Heijmans, M., Boeschoten, E.W. Perceived autonomy and self-esteem in Dutch dialysis patients: the importance of illness and treatment perceptions. Psychology \& Health: 2010, 25(6), 733-749

Ryan, 2000; Ryan, 1995). Personal control beliefs reflect individuals' beliefs regarding the extent to which one feels that one can control or influence an outcome, for example one's illness. However, people are autonomous when they act in accord with their authentic interests or integrated values and desires (Chirkov, Ryan, Kim, \& Kaplan, 2003; Deci \& Ryan, 1985, 2000; Ryan, 1995). To make the distinction more explicit, a person can feel control over carrying out an exercise program, but not feel intrinsically motivated, and thus do not act in accordance with his/her own values.

Beliefs that the illness and treatment have little impact on life showed positive associations with health related autonomy after controlling for socio-demographic and clinical variables. Patients who do not feel that the illness and the treatment impede their lives do not feel that their health stops them from doing the things they would like to do.

Considering the mean state self-esteem score it seems that the majority of the patients did not suffer from low state self-esteem. The regression analysis results revealed that the illness and treatment perceptions contributed substantially to the explanation of state self-esteem. Less concern about the illness and beliefs that the impact of the treatment on life is low were significant predictors of a higher state self-esteem.

It should be noted that a large amount of variance in perceived autonomy and state self-esteem remains still unexplained. Other psychological factors which could be of influence are the extent to which a patient is being supported by people in his immediate surroundings, like his partner, family or doctors. It can be expected that patients who are being stimulated to carry out daily activities participate more than patients who receive little support or who are being overprotected. Research focusing on these aspects is needed.

Not surprisingly, we found a low labour participation among dialysis patients compared to the general Dutch population. The results further showed that as people are younger they participate more in the labour domain, which is consistent with findings in the general Dutch population (CBS, 2006). Unfortunately, we were not able to demonstrate clear relationships between illness and treatment perceptions and labour participation, defined as performance of paid work for at least $12 \mathrm{~h}$ per week. We also investigated the relationships between number of working hours per week and illness and treatment perceptions by computing correlation coefficients, and on the whole the results were the same. Nonetheless most of these perceptions were consistently related to (un-)employment. Absence of clear relationships might be caused by the small group sizes; the number of patients of working age was very low in this study. Another possible reason for the fact that we did not find significant relationships between illness and treatment perceptions and labour participation may be the fact that the working age group was relatively old and older people might not value a paid job similarly important than younger people. The domains from which people derive their self-worth (e.g. abilities, achievements) are rather stable, but goals can be chosen moment by moment (Crocker \& Park, 2004). Possibly other life goals like doing volunteer work or carry out hobbies become more important and work moves to the background. When trying to increase feelings of autonomy and self-esteem in patients, it therefore seems important to take into account the life domains people find really important, explore their corresponding goals and focus on these goals. For younger renal patients work is probably a more important theme. Research among younger renal patients is recommended to investigate the relationship between illness and treatment perceptions and labour participation more thoroughly.

It is important to note that the present study had a cross-sectional design, which means that no conclusions can be drawn with respect to the causality of the found relationships. Thus, it is not clear whether the positive representations of the illness and treatment are a cause or a result of greater feelings of autonomy and self-esteem. Longitudinal research is necessary to investigate the direction of these relationships. Notwithstanding this limitation, our results demonstrate that especially feelings of personal control over the illness, feelings that the illness and treatment do not have that much impact on life, and less concern about the illness are important factors for autonomy and state self-esteem of ESRD patients. Another issue to note is the usage of single-item measures in this study in order to minimize the burden on respondents. Singleitem measures are sometimes viewed as less psychometrically sound than multiple-items. However, several studies demonstrate that single-item measures and their multiple counterparts are comparable (Gardner, Cummings, Dunham, \& Pierce, 1998; McKenzie \& Marks, 1999). Moreover, Gardner et al. (1998) show that a well-developed single item measure can be appropriate in avoiding common methods variance, which is often a problem with psychological measures that require respondent self-reports of attitudes, beliefs, perceptions, and the like. 
Jansen, D.L., Rijken, M., Heijmans, M., Boeschoten, E.W. Perceived autonomy and self-esteem in Dutch dialysis patients: the importance of illness and treatment perceptions. Psychology \& Health: 2010, 25(6), 733-749

The present study suggests that it may be important that paying attention to the perceptions of renal patients about their illness and the treatment should be integrated in the standard care these patients receive. Patients with the same medical condition differ in their perceptions of their illness and treatment (Weinman, Petrie, Moss-Morris, \& Horne, 1996). For this reason patients' personal beliefs about personal control, the impact of the illness and treatment on daily life and feelings of concern should be explored. Stimulating (realistic) positive beliefs and identifying and challenging negative or unhelpful beliefs might contribute to a greater sense of autonomy and self-esteem as well as to social participation in general. Petrie, Cameron, Ellis, Buick, \& Weinman (2002) demonstrated that illness perceptions of patients with a first myocardial infarction (MI) could be changed by a psychological intervention, which started when the patients were still in hospital, and resulted in improved functional outcome and earlier return to work. Although ESRD might be far more disruptive than MI, the results from the present study suggest that ESRD patients' beliefs are important for perceived autonomy and self-esteem, and other study results show that these beliefs can be changed (Karamanidou, Weinman, \& Horne, 2008; Petrie et al., 2002). There is no reason why similar interventions would not work for renal patients. In the Netherlands, psychological support is not yet a primary area of attention in renal care. It is therefore important that psychological interventions are developed and tested.

\section{Acknowledgements}

This study was supported by a grant from the Dutch Kidney Foundation and the Institute Gak Foundation, Netherlands. The nursing staffs of the participating dialysis centres are gratefully acknowledged for collecting most of the clinical data. The authors also wish to thank the staff of the NECOSAD trial office and the trial nurses and data managers of the Hans Mak Institute for their assistance in the logistics of this study.

\section{Notes}

These data were derived from the last regular survey carried out under NECOSAD-2.

\section{REFERENCES}

1. Baumeister, RF, DeWall, CN , Ciarocco, NJ and Twenge, JM (2005) Social exclusion impairs self regulation. Journal of Personality and Social Psychology 88:4 , pp. 589-604.

2. Blake, PG , Flowerdew, G. , Blake, RM and Oreopoulos, DG (1993) Serum albumin in patients on continuous ambulatory peritoneal dialysis; predictors and correlations with outcomes. Journal of the American Society of Nephrology 3 , pp. 1501-1507.

3. Braun Curtin, R , Oberly, ET , Sacksteder, P. and Friedman, A. (1996) Differences between employed and non-employed dialysis patients. American Journal of Kidney Diseases 27 , pp. 533-540.

4. Broadbent, E. , Petrie, KJ , Main, J. and Weinman, J. (2006) The brief illness perception questionnaire (BIPQ). Journal of Psychosomatic Research 60 , pp. 631-637.

5. CBS (Statistics Netherlands, 2006) StatLine. Labour and social security - Retrieved August, 2007, from

6. Chang, AM and Mackenzie, AE (1998) State self-esteem following stroke. Stroke 29:11, pp. 2325-2328.

7. Chirkov, V. , Ryan, RM , Kim, Y. and Kaplan, U. (2003) Differentiating autonomy from individualism and independence: A self-determination theory perspective on internalization of cultural orientations and wellbeing. Journal of Personality and Social Psychology 84:1 , pp. 97-110.

8. Churchill, DN, Taylor, DW, Cook, RJ , LaPlante, P. , Barre, P. Cartier, P. et al. (1992) Canadian hemodialysis morbidity study. American Journal of Kidney Diseases 19 , pp. 214-234.

9. Crocker, J. and Park, LE (2004) The costly pursuit of self-esteem. Psychological Bulletin 130:3 , pp. 392414.

10. Crocker, J. and Wolfe, CT (2001) Contingencies of self-worth. Psychological Review 108:3 , pp. 593623.

11. Deci, EL and Ryan, RM (1985) Intrinsic motivation and self-determination in human behavior Plenum Publishing Co, New York

12. Deci, EL and Ryan, RM (2000) The "what" and "why" of goal pursuits: Human needs and the selfdetermination of behavior. Psychological Inquiry 11:4 , pp. 227-268.

13. De Wit, GA, Polder, JJ , Jager, KJ and Charro, FT (2001) De maatschappelijke kosten van nierziekten in Nederland. [Social costs of renal diseases in the Netherlands]. Tijdschrift voor Gezondheidswetenschappen 79 , pp. 49-54.

14. Gardner, DG , Cummings, LL , Dunham, RB and Pierce, JL (1998) Single-item versus multiple-item measurement scales: An empirical comparison. Educational and Psychological Measurement 58 , pp. 898-915. 
Jansen, D.L., Rijken, M., Heijmans, M., Boeschoten, E.W. Perceived autonomy and self-esteem in Dutch dialysis patients: the importance of illness and treatment perceptions. Psychology \& Health: 2010, 25(6), 733-749

15. Grassmann, A. , Gioberge, S. , Moeller, S. and Brown, G. (2005) ESRD patients in 2004: Global overview of patient numbers, treatment modalities and associated trends. Nephrology Dialysis Transplantation 20:12, pp. 2587-2593.

16. Greenberg, GD and Peterson, RA (2002) Illness effects questionnaire-Multi-perspective (IEQ-MP): Users manual Multi- Health Systems Inc, Toronto, Canada

17. Griva, K. , Jayasena, D. , Davenport, A. , Harrison, M. and Newman, SP (2009) Illness and treatment cognitions and health related quality of life in end stage renal disease. British Journal of Health Psychology 14:1, pp. 17-34.

18. Hagger, MS and Orbell, S. (2003) A meta-analytic review of the common-sense model of illness representations. Psychology and Health 18:2, pp. 141-184.

19. Heatherton, TF and Polivy, J. (1991) Development and validation of a scale for measuring state selfesteem. Journal of Personality and Social Psychology 60:6 , pp. 895-910.

20. Heijmans, MJWM and Rijken, PM (2004) Sociaal-maatschappelijke participatie van mensen met een chronische nierinsufficiëntie. Een literatuurstudie naar de ervaren knelpunten en mogelijkheden NIVEL , Utrecht, The Netherlands - [Social participation of people with chronic renal insufficiency. A literature study on experienced obstacles and possibilities]

21. Horne, R. Cameron, LD and Leventhal, H. (eds) (2003) Treatment perceptions and self regulation. The self regulation of health and illness behaviour pp. 138-153. Routledge , London

22. Horne, R. , Buick, D. , Fisher, M. , Leake, H. , Cooper, V. and Weinman, J. (2004) Doubts about necessity and concerns about adverse effects: Identifying the types of beliefs that are associated with non-adherence to HAART. International Journal of STD \& AIDS 15 , pp. 38-44.

23. Hyde, M. , Wiggins, RD , Higgs, P. and Blane, DB (2003) A measure of quality of life in early old age: The theory, development and properties of a needs satisfaction model (CASP-19). Aging and Mental Health 7:3, pp. 186-194.

24. Karamanidou, C. , Weinman, J. and Horne, R. (2008) Improving haemodialysis patients' understanding of phosphate-binding medication: A pilot study of a psycho-educational intervention designed to change patients' perceptions of the problem and treatment. British Journal of Health Psychology 13 , pp. 205-214.

25. Leventhal, H. , Meyer, D. and Nerenz, D. Rachman, S. (ed) (1980) The common sense representation of illness danger. Medical psychology pp. 7-30. Pergamon, New York

26. Leventhal, H. , Nerenz, DR and Steele, DJ Baum, A. , Taylor, SE and Singer, JE (eds) (1984) Illness representations and coping with health threats. Handbook of psychology and health pp. 219-252. Lawrence Erlbaum Associates, Hillsdale, NJ

27. Lowrie, EG and Lew, NL (1990) Death risk in hemodialysis patients: The predictive value of commonly measured variables and an evaluation of death rate differences between facilities. American Journal of Kidney Diseases 15:5, pp. 458-482.

28. Marmot, M. , Banks, J. , Blundell, R. , Lessof, C. and Nazroo, J. (2003) Health, wealth and lifestyles of the older population in England: The 2002 english longitudinal study of ageing University College, Institute for Fiscal Studies, London

29. McKenzie, N. and Marks, I. (1999) Quick rating of depressed mood in patients with anxiety disorders. The British Journal of Psychiatry 174 , pp. 266-269.

30. Moss-Morris, R. , Weinman, J. , Petrie, KJ , Horne, R. , Cameron, LD and Buick, D. (2002) The revised illness perception questionnaire (IPQ-R).

31. Murtagh, FEM , Addington-Hall, J. and Higginson, IJ (2007) The prevalence of symptoms in end-stage renal disease: A systematic review. Advances in Chronic Kidney Disease 14:1, pp. 82-99.

32. Oppe, M. , Treur, MJ , Barendregt, W. and de Charro, FTh (2007) Statistisch verslag 2007. De ontwikkeling van het nierfunctievervangingsprogramma in Nederland gedurende de periode 1990-2006. Stichting Renine, Renal Replacement Registry Netherlands, Rotterdam, The Netherlands

33. Paradise, AW and Kernis, MH (2002) Self-esteem and psychological well-being: Implications of fragile self-esteem. Journal of Social and Clinical Psychology 21 , pp. 345-361.

34. Petrie, KJ , Cameron, LD , Ellis, CJ , Buick, D. and Weinman, J. (2002) Changing illness perceptions after myocardial infarction: An early intervention randomised controlled trial. Psychosomatic Medicine $64: 4$, pp. $580-586$.

35. Petrie, KJ , Jago, LA and Devcich, DA (2007) The role of illness perceptions in patients with medical conditions. Current Opinion in Psychiatry 20 , pp. 163-167.

36. Petrie, KJ , Weinman, J. , Sharpe, N. and Buckley, J. (1996) Role of patients' view of their illness in predicting return to work and functioning after myocardial infarction: A longitudinal study. British Medical Journal 312 , pp. 1191-1194.

37. Plantinga, LC , Fink, NE , Levin, NW , Jaar, BG , Coresh, J. Levey, AS et al. (2007) Early, intermediate, and long-term risk factors for mortality in incident dialysis patients: The Choices for Healthy Outcomes in Caring for ESRD (CHOICE) Study. American Journal of Kidney Diseases 49:6 , pp. 831-840. 
Jansen, D.L., Rijken, M., Heijmans, M., Boeschoten, E.W. Perceived autonomy and self-esteem in Dutch dialysis patients: the importance of illness and treatment perceptions. Psychology \& Health: 2010, 25(6), 733-749

38. Rasgon, S. , Schwankovsky, L. , James-Rogers, A. , Widrow, L. , Glick, J. and Butts, E. (1993) An intervention for employment maintenance among blue-collar workers with end stage renal disease. American Journal of Kidney Diseases 22:3 , pp. 403-412.

39. Reis, HT , Sheldon, KM , Gable, SL, Roscoe, J. and Ryan, RM (2000) Daily well-being: The role of autonomy, competence, and relatedness. Personality and Social Psychology Bulletin 26:4 , pp. $419-435$.

40. Ryan, RM (1995) Psychological needs and the facilitation of integrative processes. Journal of Personality 63:3 , pp. 397-427.]

41. Stichting Renine (2005) Renal Replacement Registry Netherlands, Rotterdam, The Netherlands Retrieved August 2007, from

42. Taylor, M. , Brice, J., Buck., N and Prentice-Lane, E. (2003) British household panel survey user manual (Vol. A). Introduction, technical report and appendices University of Essex, UK Data Archive , Colchester, Essex

43. Termorshuizen, F. , Korevaar, JC, Dekker, FW , Jager, KJ , Van Manen, JG Boeschoten, EW et al. (2003) Time trends in initiation and dose of dialysis in end-stage renal disease patients in The Netherlands. Nephrology Dialysis Transplantation 18 , pp. 552-558.

44. Timmers, L. , Thong, M. , Dekker, FW , Boeschoten, EW , Heijmans, MJWM Rijken, PM et al. (2008) Illness perceptions in dialysis patients and their association with quality of life. Psychology and Health 23:6, pp. 679-690.

45. Van der Mei, SF, Van Sonderen, ELP, Van Son, WJ , De Jong, PE , Groothoff, JW and Van den Heuvel, WJA (2007) Social participation after successful kidney transplantation. Disability and Rehabilitation 29:6, pp. 473-483.

46. Van Manen, JG , Korevaar, JC , Dekker, FW , Reuselaars, MC, Boeschoten, EW and Krediet, RT (2001) Changes in employment status in end-stage renal disease patients during the first year of dialysis. Peritoneal Dialysis International 21:6, pp. 595-601.

47. Waddell, G. and Burton, AK (2006) Is work good for your health and well being? The Stationery Office , London

48. Weinman, J. , Petrie, KJ , Moss-Morris, R. and Horne, R. (1996) The illness perception questionnaire: A new method for assessing the cognitive representation of illness. Psychology and Health 11 , pp. 431446. 


\section{TABLES}

\section{LIST OF TABLES}

Table 1. Socio-demographic and clinical characteristics of the total sample.

\section{Total sample}

*Due to rounding the sum of percentages is $>100 \%$.

**Normal serum albumin values are 40-50 g L

Gender- $N(\%)$

Male

Female

Age, mean in years (SD)

Age, in groups- $N(\%)^{*}$

18-49 years

50-64 years

$\geq 65$ years

Educational level- $N(\%)$

Low

Moderate

High

Marital status- $N(\%)$

Married/living together

Living alone

Type of treatment- $N$ (\%)

Haemodialysis

Peritoneal dialysis

Time on dialysis, mean in years (SD)

Time on dialysis, in groups- $N(\%)$

Up to 2 years

2-5 years

5-10 years

39

Serum albumin, mean in $\mathrm{g} \mathrm{L}(\mathrm{SD})^{* *}$ 
Table 2. Mean scores, standard deviations $(N=154-157)$ and Pearson's correlations $(N=151-156)$ of illness perceptions, treatment perceptions, perceived autonomy and state self-esteem (total sample).

\begin{tabular}{|c|c|c|c|c|c|c|c|c|c|c|}
\hline & $\begin{array}{c}\text { M } \\
\text { (SD) }\end{array}$ & 1 & 2 & 3 & 4 & 5 & 6 & 7 & 8 & 9 \\
\hline \multicolumn{11}{|c|}{$* p<0.05 ; * * p<0.01 ; * * * p<0.001}$. \\
\hline Consequences & $\begin{array}{r}7.73 \\
(2.01)\end{array}$ & & & & & & & & & \\
\hline Timeline & $\begin{array}{r}9.19 \\
(1.68)\end{array}$ & 0.07 & & & & & & & & \\
\hline $\begin{array}{l}\text { Personal } \\
\text { control }\end{array}$ & $\begin{array}{r}4.91 \\
(3.20)\end{array}$ & $-0.17 *$ & -0.01 & & & & & & & \\
\hline $\begin{array}{l}\text { Treatment } \\
\text { control }\end{array}$ & $\begin{array}{r}8.28 \\
(2.03)\end{array}$ & 0.14 & $0.31 * * *$ & $0.16^{*}$ & & & & & & \\
\hline Identity & $\begin{array}{r}6.14 \\
(2.43)\end{array}$ & $0.43 * * *$ & -0.02 & $-0.20^{*}$ & 0.03 & & & & & \\
\hline Concern & $\begin{array}{r}6.31 \\
(3.00)\end{array}$ & $0.35 * * *$ & -0.05 & -0.07 & -0.01 & $0.50 * * *$ & & & & \\
\hline Understanding & $\begin{array}{r}7.66 \\
(2.70)\end{array}$ & -0.01 & 0.10 & $0.23 * *$ & $0.23 * *$ & $0.25 * *$ & 0.13 & & & \\
\hline $\begin{array}{l}\text { Emotional } \\
\text { response }\end{array}$ & $\begin{array}{r}4.96 \\
(3.22)\end{array}$ & $0.38 * * *$ & -0.09 & -0.05 & -0.07 & $0.43 * * *$ & $0.71 * * *$ & 0.01 & & \\
\hline $\begin{array}{l}\text { Treatment } \\
\text { disruption }\end{array}$ & $\begin{array}{r}63.40 \\
(25.04)\end{array}$ & $0.43 * * *$ & -0.04 & $-0.26 * *$ & -0.12 & $0.56 * * *$ & $0.52 * * *$ & -0.03 & $0.62 * * *$ & \\
\hline $\begin{array}{c}\text { Global } \\
\text { autonomy }\end{array}$ & $\begin{array}{r}1.60 \\
(0.78)\end{array}$ & $-0.24 * *$ & 0.06 & $0.30 * * *$ & $0.16^{*}$ & $0.28 * * *$ & $-0.24 * *$ & $0.20 *$ & $-0.20 *$ & $0.34 * * *$ \\
\hline $\begin{array}{l}\text { Health related } \\
\text { autonomy }\end{array}$ & $\begin{array}{r}1.21 \\
(0.92)\end{array}$ & $0.39^{* * *}$ & -0.06 & $0.17 *$ & -0.04 & $-0.28 * *$ & $0.29 * * *$ & -0.12 & $0.41 * * *$ & $0.40^{* * *}$ \\
\hline $\begin{array}{l}\text { State self- } \\
\text { esteem }\end{array}$ & $\begin{array}{r}76.47 \\
(10.86)\end{array}$ & $-0.26^{* *}$ & 0.05 & $0.21 *$ & $0.18^{*}$ & 0.30 *** & $0.47 * * *$ & $0.21 * *$ & $0.52 * * *$ & $0.60 * * *$ \\
\hline
\end{tabular}

Table 3. Differences in mean illness and treatment perceptions scores between employed and unemployed patients of working age (18-64 years).

\section{Employed}

Consequences

Timeline

Personal control

Treatment control

Identity

Concern

Understanding

Emotional response

Treatment disruption

\begin{tabular}{lllllrl}
$\boldsymbol{N}$ & \multicolumn{1}{c}{$\boldsymbol{M ( \mathbf { S D } )}$} & $\boldsymbol{N}$ & $\boldsymbol{M}(\mathbf{S D})$ & $\boldsymbol{t}$ & $\boldsymbol{d} \mathbf{}$ & $\boldsymbol{p}$ \\
15 & $7.53(1.68)$ & 40 & $8.30(1.98)$ & 1.330 & 53 & 0.189 \\
15 & $8.13(2.56)$ & 40 & $8.65(1.96)$ & 0.801 & 53 & 0.427 \\
15 & $5.53(3.85)$ & 40 & $4.48(3.58)$ & -0.957 & 53 & 0.343 \\
15 & $7.53(2.59)$ & 40 & $8.45(2.25)$ & 1.291 & 53 & 0.202 \\
15 & $5.53(1.55)$ & 40 & $6.78(2.58)$ & 2.173 & 41.846 & 0.036 \\
15 & $6.80(2.46)$ & 40 & $6.80(3.35)$ & 0.000 & 53 & 1.000 \\
15 & $7.13(3.07)$ & 40 & $8.25(2.50)$ & 1.386 & 53 & 0.172 \\
15 & $5.27(2.63)$ & 40 & $5.65(3.22)$ & 0.411 & 53 & 0.682 \\
15 & $62.19(25.29)$ & 38 & $71.99(25.29)$ & 1.271 & 51 & 0.209
\end{tabular}


Table 4. Hierarchical multiple linear regression models to predict perceived global autonomy in dialysis patients (total sample).

Model 1 (block Model 2 (block $1+$ Model 3 (block $1+2+$

1)

$$
(N=105) \beta
$$

2)

3)

$(N=105) \beta$

${ }^{*} p<0.05 ; * * p<0.01 ; * * * p<0.001$.

Block 1: Socio-demographic characteristics

Age in years

$-0.05$

0.03

Female (ref: male)

$-0.06$

$-0.06$

Educational level (ref: low)

Moderate

0.18

0.21 *

High

$0.28 *$

$0.26^{*}$

$0.25 *$

Marital status (ref: married/living together)

0.09

0.13

Block 2: Clinical characteristics

Serum albumin

$-0.02$

PD treatment (ref: HD)

$0.22 *$

0.10

Time on dialysis in years

$-0.07$

$-0.06$

Block 3: Perceptions

Consequences

Timeline

0.14

Personal control

$0.29 * *$

Treatment control

Identity

$-0.08$

Concern

0.12

Understanding

0.12

Treatment disruption

$-0.25$

Adjusted $R^{2}$

0.04

0.06

$0.24 * * *$

$F$ change model

1.83

1.70

$3.95 * * *$ 
Table 5. Hierarchical multiple linear regression models to predict perceived health related autonomy in dialysis patients (total sample).

Model 1 (block Model 2 (block $1+$ Model 3 (block $1+2+$ 1)

$$
(N=105) \beta \quad(N=105) \beta \quad(N=105) \beta
$$

$* p<0.05 ; * * p<0.01 ; * * * p<0.001$.

Block 1: Socio-demographic characteristics

Age in years

Female (ref: male)

Educational level (ref: low)

Moderate

High

Marital status (ref: married/living together)

Block 2: Clinical characteristics

Serum albumin

PD treatment (ref: HD)

Time on dialysis in years

Block 3: Perceptions

Consequences

Timeline

Personal control

Treatment control

Identity

Concern

Understanding

Treatment disruption

Adjusted $R^{2}$

$F$ change model
0.05

0.07

$-0.11$

$-0.11$

0.02

$-0.04$

0.05

0.02

0.05

0.06

0.02

$$
-0.26^{*}
$$

0.14

0.10

0.03

$-0.03$

$-0.01$

$-0.18$

$-0.32 *$

$-0.04$

$-0.06$

$0.18^{* *}$

0.30

0.20 
Table 6. Hierarchical multiple linear regression models to predict state self-esteem in dialysis patients (total sample).

Model 1 (block Model 2 (block $1+$ Model 3 (block $1+2+$

1)

$$
(N=105) \beta
$$

$* p<0.05 ; * * p<0.01 ; * * * p<0.001$.

Block 1: Socio-demographic characteristics

Age in years

0.02

0.09

$-0.20$

0.08

0.12

$-0.09$

Marital status (ref: married/living together)

Block 2: Clinical characteristics

Serum albumin

0.19

0.12

PD treatment (ref: HD)

Time on dialysis in years

Block 3: Perceptions

Consequences

Timeline

Personal control

Treatment control

Identity

Concern

Understanding

Treatment disruption

Adjusted $R^{2}$

$F$ change model
2)

3)

$(N=105) \beta$ 